\title{
Nucleic acid detection with surface plasmon resonance using cationic latex
}

\author{
E. F. A. de Vries, R. B. M. Schasfoort, J. van der Plas \\ Netherlands Organization for Applied Scientific Research (TNO), Department of Microbiology, P.O. Box 360, \\ 3700 AJ Zeist, The Netherlands
}

\begin{abstract}
J. Greve
University of Twente, Department of Applied Physics, P.O. Box 217, 7500 AE Enschede, The Netherlands
\end{abstract}

(Received 8 March 1993; revised 18 February 1994; accepted 28 February 1994)

\begin{abstract}
An affinity sensor based on Surface Plasmon Resonance (SPR) was used to detect nucleic acids. SPR is an optical technique that is able to detect small changes in the refractive index of the immediate vicinity of a metal surface. After a specific amplification of DNA, achieved using the polymerase chain reaction (PCR), detection was accomplished through the application of latex particle intermediates. The assay was based on the inhibition of latex particle adsorption to a metal surface by DNA. The amount of latex present determined the sensitivity of the inhibition assay. The adsorption behaviour of latex particles at a gold surface was investigated using SPR. The parameters that played an important role in this adsorption were ionic strength and $\mathrm{pH}$.
\end{abstract}

Keywords: surface plasmon resonance, latex, nucleic acids, polymerase chain reaction.

\section{INTRODUCTION}

Amplification of nucleic acids, for example, by PCR (Saiki et al., 1988), has revolutionised diagnostics in the fields of both genetics and microbiology. The presence of certain sequences in the nucleotide chain results in the amplification of a specific segment of DNA or RNA. These amplification products are usually analysed by gel electrophoresis or by hybridisation. Such techniques are laborious and can only be performed by specialists. The combination of the automated amplification process with an auto- mated detection device, such as a biosensor, would be most desirable.

A biosensor can selectively detect specific biological molecules and transmit this detection in the form of an electrical signal. Surface Plasmon Resonance (SPR) is an optical technique which can be used as the transducing basis of a biosensor (Daniels et al., 1988; Kooyman et al., 1990; Mayo \& Hallock, 1989). SPR affinity sensors are based on the measurement of changes in the refractive index of the immediate vicinity of a metal surface. When monochromatic light, polarised in the plane of incidence, is reflected 
by a metal layer (e.g. gold evaporated onto a glass slide), the reflectance is minimal at a certain angle. This reflectance minimum is sensitive to changes in the refractive index of the medium adjacent to the metal layer. For a comprehensive discussion of SPR see Raether, 1977.

The sensitivity of SPR depends on the molecular weight of the ligand, present in the adjacent medium, which becomes adsorbed at the metal surface. Large molecules cause a considerable change in refractive index. SPR can therefore be applied to detect these molecules directly. However, small molecules are difficult to detect because they cause only small changes in refractive index. However, the sensitivity of the SPR sensor to small molecules can be improved by the addition of cationic latex particles to the adjacent medium in order to effect amplification. These particles cause a large change of refractive index in the vicinity of a metal surface when they adsorb at the surface. This, in time, causes a large shift in the plasmon resonance angle.

Here we describe the application of the SPR technique to detect PCR-amplified DNA. The shift in plasmon resonance angle, caused by adsorption of the cationic latex particles, was inversely related to the DNA concentration. The influence of DNA concentration on the SPR angle shift was determined indirectly in a latex adsorption inhibition assay. Parameters such as $\mathrm{pH}$, ionic strength and the zeta potential, which are involved in the adsorption process, were also studied.

\section{MATERIALS AND METHODS}

Biocryl latex BPA 1000 (10\% solid) was purchased from Toso-Haas (Stuttgart, Germany). Glass slides (BN 845 432-T) were purchased from Balzers (Liechtenstein). Tris and EDTA were purchased from Merck (Darmstadt, Germany). DNA from Herring testes was purchased from Sigma chemicals (St. Louis, MO). Chemicals used in the PCR reaction were purchased from BRL. Zeta-potential measurements were carried out using a Delsa 440 from Coulter (Mijdrecht, The Netherlands).

\section{Surface plasmon resonance}

The SPR device uses a vibrating mirror to direct monochromatic light at a metal surface at different angles (Kooyman et al., 1991). The angle of the reflectance minimum, which changes with the refractive index, was recorded. An angular resolution of approximately $2 \cdot 10^{-3}$ degrees can be obtained using this device.

Glass slides were coated with a 2 nm thick chrome layer, and next with a gold layer of approximately $50 \mathrm{~nm}$ thickness. Before use, these coated slides were cleaned using ethanol, toluene and again ethanol. The surface of the coated slides remained hydrophobic after cleaning. The area of the sensor surface was approximately $0.75 \mathrm{~cm}^{2}$. Immersion oil was used to obtain a good optical contact between the prism and the glass slides. The adsorption experiments were carried out at room temperature.

\section{Latex inhibition assay}

The DNA detection experiments were performed in TE-buffer $(10 \mathrm{mM}$ Tris. $\mathrm{HCl}, 1 \mathrm{mM}$ EDTA, $\mathrm{pH} 8 \cdot 0$ ). A solution of $250 \mu \mathrm{l}$ buffer was mixed with $25 \mu \mathrm{l} \mathrm{PCR-mixture.} \mathrm{Subsequently} 1.5 \mu \mathrm{l}$ latex solution ( $1 \%$ solids) was then added to this mixture which was subsequently transferred to the cuvette. The solution was mixed during measurement by pumping a volume of approximately $75 \mu \mathrm{l}$ in and out of the cuvette with a frequency of approximately 30 times per minute.

The influence of $\mathrm{pH}$ on the adsorption of latex to the gold surface was studied using the following buffer solutions: $5 \mathrm{mM}$ Na-acetate/Acetic acid, pH 4.0; $5 \mathrm{mM}$ MES/NaOH, pH 6.0; $5 \mathrm{mM}$ Tris/ $\mathrm{HCl}$, pH 8.0; $5 \mathrm{mM}$ Glycine/ $\mathrm{NaOH}$, ph $10 \cdot 0$.

The influence of ionic strength on adsorption behaviour was determined in a $\mathrm{NaCl}$ solution at $\mathrm{pH} 6 \cdot 5 \pm 0 \cdot 3$.

\section{Polymerase chain reaction}

Amplification reactions were performed in $50 \mu \mathrm{l}$ of a reaction mixture containing $20 \mathrm{mM}$ Tris $\cdot \mathrm{HCl}$, pH 7.7; $50 \mathrm{mM} \mathrm{KCl} ; 1.5 \mathrm{mM} \mathrm{MgCl}_{2} ; 0.01 \%$ gelatin; $200 \mu \mathrm{M}$ each of dATP, dGTP, dCTP, and dTTP; 50 pmol primer; 10 ng DNA; 1 unit Taq polymerase. The primers used were 18mer oligonucleotides. The PCR reaction was performed in a Bioexcellence PHC-2 from Biores (Woerden, The Netherlands), programmed for 40 cycles of $1 \mathrm{~min}$ at $94^{\circ} \mathrm{C}, 1 \mathrm{~min}$ at $50^{\circ} \mathrm{C}$ and $2.5 \mathrm{~min}$ at $72^{\circ} \mathrm{C}$, using the highest ramp rate between each temperature. Amplification products were analysed using electrophoresis in a 
$1.5 \%$ agarose gel and detected by staining with ethidium bromide $(50 \mu \mathrm{g} / \mathrm{l})$.

\section{RESULTS}

DNA amplified in a PCR mixture can be detected using a latex inhibition assay as illustrated in Fig. 1. It is possible to discriminate between positive and negative PCRs at a latex concentration of $0.006 \%(\mathrm{v} / \mathrm{v})$. Nucleotides and primers, also present in the PCR reaction mixture, did not interfere with the measurements.

In theory, the adsorption behaviour of the latex particles would play an important role in this assay. Factors affecting such behaviour are latex concentration, ionic strength and $\mathrm{pH}$. The response of the sensor to different concentrations of latex is presented in Fig. 2. As can bc seen, the sensor surface became saturated at a latex concentration of $0 \cdot 004 \%$. (A latex concentration of $0.001 \%$ corresponds to approximately 32 picomoles latex particles per litre.) The influence of ionic strength on the adsorption behaviour of latex is shown in Fig. 3. As can be seen, the ionic strength dramatically influenced the maximum amount of latex adsorbed to the coated surface. No flocculation of latex was observed under the conditions used. The influence of $\mathrm{pH}$ on the adsorption behaviour of latex is shown in Fig. 4. The amount of latex which adsorbed at the gold surface increased with an increasing $\mathrm{pH}$.

Experiments with different types of latex particles, such as polystyrene latex and latex carrying carboxylic groups, showed that these particles can also adsorb at a gold surface. However, the

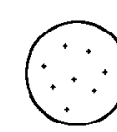

Latex
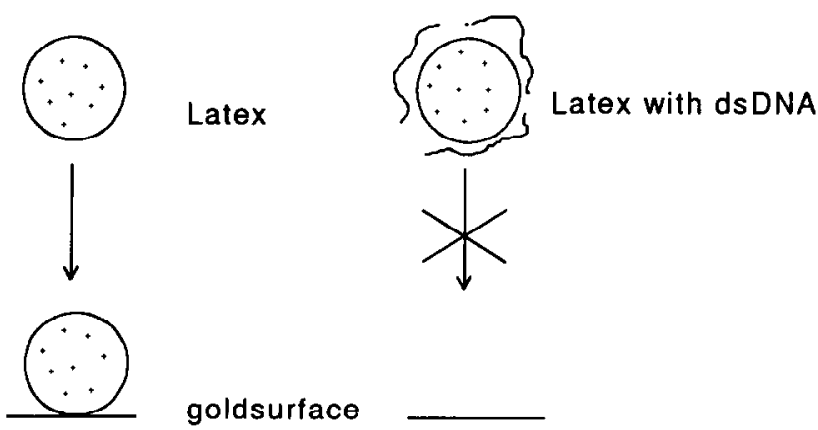

goldsurface

Fig. 1. Latex inhibition assay: Binding of positively charged latex to the metal surface is inhibited by negatively charged dsDNA fragments.

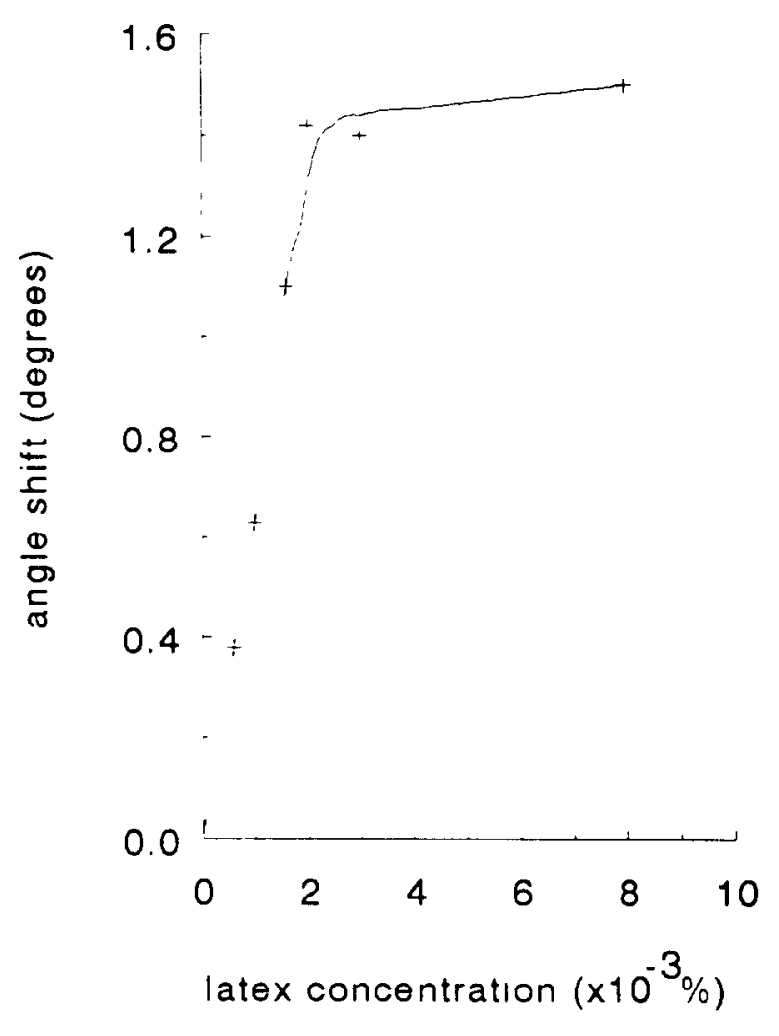

Fig. 2. Relation between latex concentration and maximal angle shift. The experiments were performed in TE-buffer pH 8.0, with a volume of $250 \mu l$.

conditions for adsorption of these types of latex, such as ionic strength and $\mathrm{pH}$, were different.

The relationship between angle shift and dsDNA concentration at two different concentrations of latex is presented in Fig. 5, which shows that the angle shift decreased from 1.6 degrees to $0 \cdot 2$ degrees with an increasing DNA concentration. The remaining angle shift was probably caused by some non-inhibited adsorption of particles at the gold surface because these experiments were performed using pure dsDNA solutions.

Proteins can adsorb at the gold surface and bind to latex. In contrast to DNA, such compounds do not usually differ in concentration in a PCR. In order to investigate the effect of protein on the assay, experiments were carried out using different concentrations of Bovine Serum Albumin (BSA). In TE-buffer, BSA adsorbs well to a gold surface. When BSA was present in the range of $15-20 \mu \mathrm{g}$, the latex adsorption was influenced by the presence of the protein. Adsorption of BSA at the gold surface was diminished by using a buffer containing $\mathrm{NaCl}$. In TE-buffer containing $0.5 \mathrm{M} \mathrm{NaCl}$, adsorption of $\mathrm{BSA}$ at 


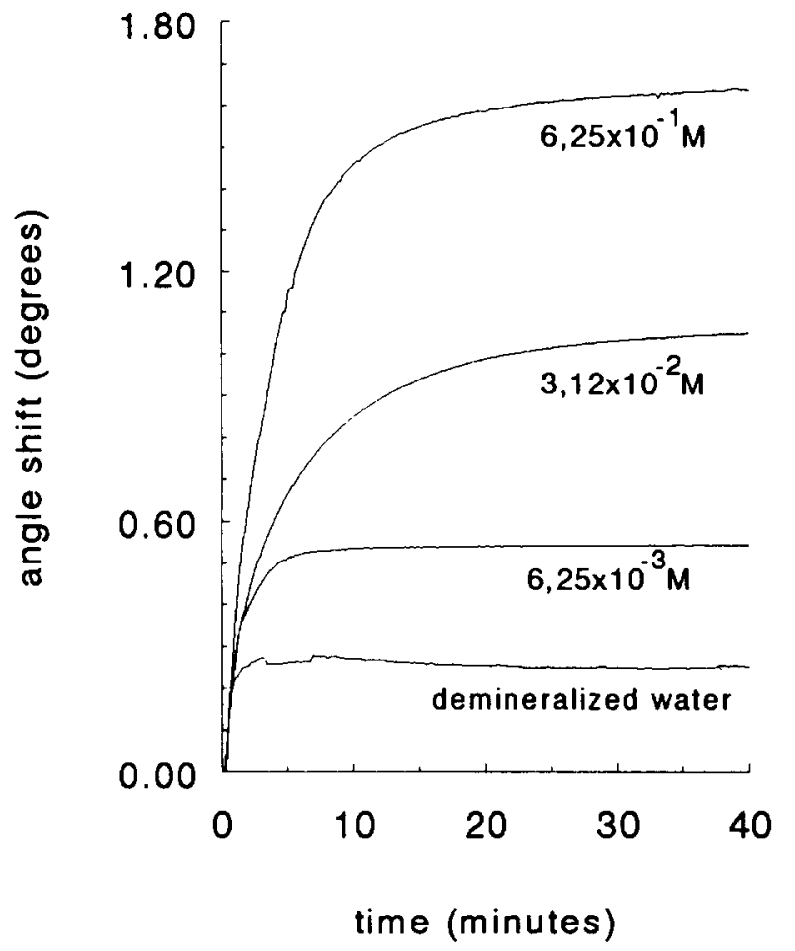

Fig. 3. Adsorption curves for the latex particles under different conditions of ionic strength. Experiments were performed in a volume of $250 \mu$ with a latex concentration of $0.003 \%$.

the gold surface was reduced dramatically. Under these conditions, latex adsorption was not affected by the presence of $\mathrm{BSA}$. Adding $\mathrm{NaCl}$ to a concentration of $0.6 \mathrm{M}$ did not affect the assay.

Electrostatic interactions may also play an important role in the adsorption process. The zeta-potential of a latex particle can be used as an indicator of its electrokinetic behaviour under different conditions. The influence of $\mathrm{pH}$, ionic strength and the presence of DNA on the zetapotential was investigated. Under all conditions the zeta-potential of the particles was positive. The potential remained totally unaffected upon varying the $\mathrm{pH}$ between 4 and 10 . However, with increasing ionic strength $(0.06 \mathrm{M} \mathrm{NaCl}-0.6 \mathrm{M}$ $\mathrm{NaCl}$ ), the potential decreased from $+33 \mathrm{mV}$ to $+12 \mathrm{mV}$. In the presence of DNA the potential immediately decreased to $+12 \mathrm{mV}$.

\section{DISCUSSION}

DNA, itself, did not adsorb at the gold surface in a TE-buffer solution. An important parameter

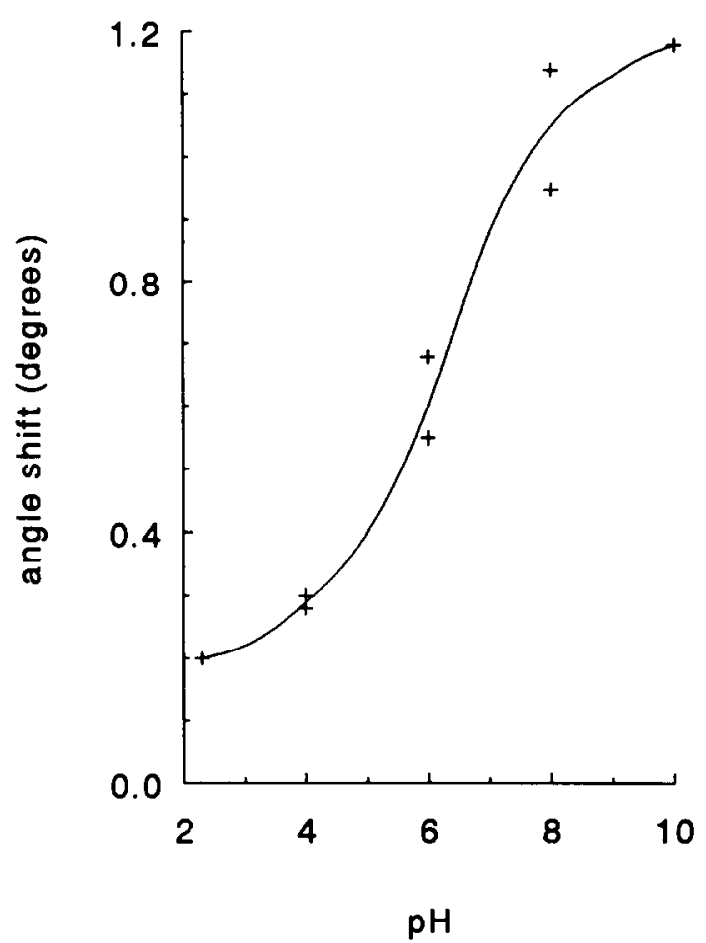

Fig. 4. Relationship between $\mathrm{pH}$ and angle shift. Latex concentration was $0.004 \%$ and the volume was $250 \mu \mathrm{l}$.

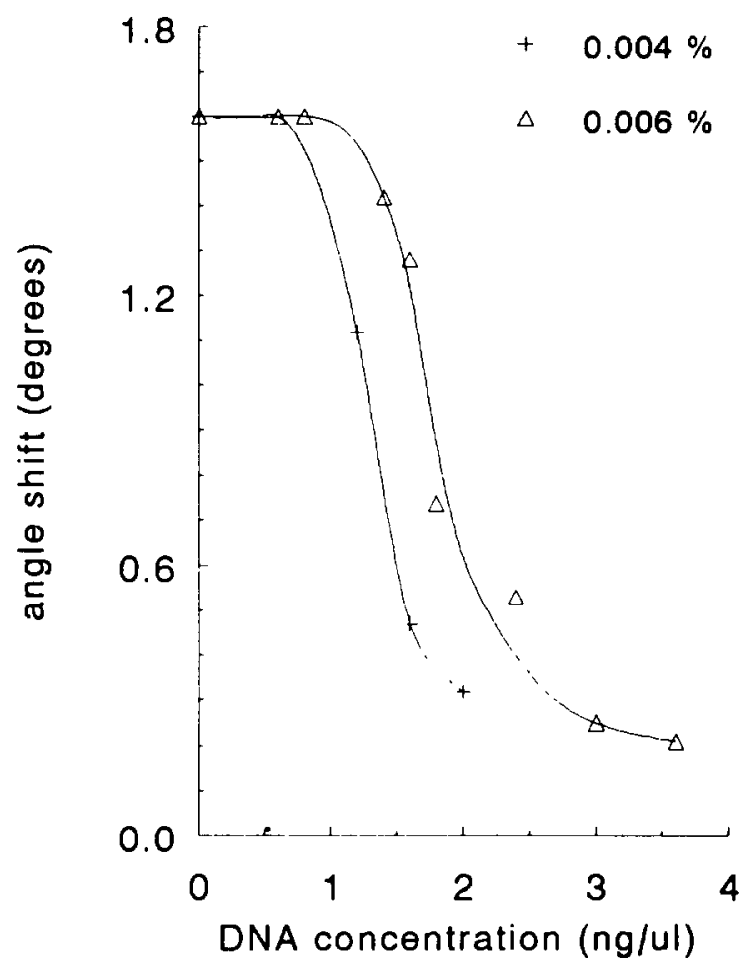

Fig. 5. Relationship between DNA concentration and angle shift. Two latex concentrations were used. Experiments were performed in TE-buffer, $p H$ 8.0, with a volume of $250 \mu \mathrm{l}$. 
that determines the adsorption behaviour of DNA is the presence of bivalent cations (Romanowski $e t$ al., 1991). Experiments carried out in $10 \mathrm{mM}$ Tris buffer, $\mathrm{pH} 8.0$, containing $5 \mathrm{mM} \mathrm{MgCl}_{2}$ supported this observation. A solution of $250 \mu \mathrm{l}$ buffer containing $10 \mathrm{ng} / \mu \mathrm{lDNA}$ and $5 \mathrm{mM} \mathrm{MgCl}{ }_{2}$ caused a shift in the angle of the reflectance minimum of approximately 0.2 degrees.

Adsorption of latex at the gold layer caused a large angle shift of 1.6 degrees. The latex particles, made of polymetacrylate ester, contained quaternary ammonium groups and had a diameter of approximately $100 \mathrm{~nm}$. Once the particles were adsorbed, attempts to desorb them by changing the aqueous conditions (ionic strength, $\mathrm{pH}$ ) or by rinsing the solution vigorously, were unsuccessful. Adsorption of these particles onto gold would appear to be irreversible.

The interaction between latex particles and the gold surface seems to be mainly hydrophobic in character. The observed influence of ionic strength on latex adsorption was probably caused by the shielding of cationic charges. Lateral repulsive forces, caused by electric charges, determined the amount of latex which adsorbed at the surface. These repulsive forces can change into attractive forces at high ionic strength (Vincent et. al., 1978).

Adsorption isotherms were also influenced by the $\mathrm{pH}$ wheras the zeta-potential did not change with the $\mathrm{pH}$. This indicated that the interaction between the gold surface and a latex particle is influenced by $\mathrm{pH}$.

If high concentrations of latex $(0 \cdot 1 \%$ solid $)$ and DNA were mixed, an aggregation was observed. These DNA-latex aggregates did not cause a shift in the plasmon resonance angle. Mixing prevented the aggregates from precipitating at the metal surface. In the assay conditions used, the concentrations of the latex and DNA were too low to cause an aggregation of the latex particles.

Amplified DNA sequences, of length between $200 \mathrm{bp}$ and $3000 \mathrm{bp}$ were tested. The assay responded uniformly to all sequence lengths.

The influence of BSA on the assay was investigated to determine the effect of proteins on the assay. Proteins and other components in the PCR mixture can adsorb at the gold surface but they cause a maximum angle shift of 0.2 degrees, which is small when compared to the angle shift caused by the adsorption of latex particles. BSA was used in this study as a model protein. Generally, the influence of proteins in cases such as this depends on their adsorption behaviour, which, in turn, is often influenced by ionic strength. The assay can be used in a TEbuffer with a salt concentration in the range of 0 to $0.6 \mathrm{M} \mathrm{NaCl}$.

Mixing of the solution during the measurements appeared to be an absolute requirement. Adsorption isotherms could only be compared when the solution was mixed. The kinetics of adsorption were influenced strongly by mixing. Within 10 minutes, $90 \%$ of maximum latex adsorption was reached.

\section{CONCLUSIONS}

Latex particles adsorbed strongly to the gold surface of the SPR sensor. They can therefore act as an amplifying intermediate between the compound which has to be detected and the inert gold surface. It has been shown that cationic latex particles can be used in an inhibition assay to detect dsDNA. The large angle shift discriminates between adsorption of latex particles and other nonspecific effects. Important parameters that should be controlled are $\mathrm{pH}$ and ionic strength.

Advantages of this system are the simple configuration and rapidness of the assay. In addition, the use of dangerous chemicals is omitted.

\section{ACKNOWLEDGEMENT}

This research was supported by the Dutch technology foundation (STW).

\section{ABBREVIATIONS}

TE: $10 \mathrm{mM}$ Tris and $1 \mathrm{mM}$ EDTA pH $8 \cdot 0$; PCR: Polymerase Chain Reaction; SPR: Surface Plasmon Resonance; MES: 2-[N-Morpholino] ethanesulphonic acid; bp: basepairs.

\section{REFERENCES}

Daniels, P.B., Deacon, J.K., Eddowes, M.J. \& Pedley, D.G. (1988). Surface plasmon resonance applied 
to immunosensing. Sensors and Actuators, 15, 11-18.

Kooyman, R.P.H., de Bruijn, H.E., Eenink, R.G. \& Greve, J. (1990). Surface Plasmon Resonance as a bioanalytical tool. J. Mol. Struct., 218, 345-350. Kooyman, R.P.H., Lenferink, A.T.M., Eenink, R.G. \& Greve. J. (1991). Vibrating mirror Surface Plasmon Resonance immunosensor. Anal. Chem., 63, $83-85$.

Mayo, C.S. \& Hallock, R.B. (1989). Immunoassay based on surface plasmon oscillations. J. Immunol. Meth., 120, 105-114.

Raether, H. (1977). In: Physics of Thin Films, Vol 9 (G. Hass, M. Francombe, \& R. Hoffman, eds), Academic Press, New York, pp 145-261.
Romanowski, G., Lorenz, M.G. \& Wackernagel, W. (1991). Adsorption of plasmid DNA to mineral surfaces and protection against DNase I. Appl. Environ. Microbiol., 57, 1057-1061.

Saiki, R.K., Gelfand, D.H., Stoffel, S., Scharf, S.J., Higuchi. R.J., Horn, G.T., Mullis, K.B. \& Erlich, H.A. (1988). Primer-Directed enzymatic amplification of DNA with a thermostable DNA Polymerase. Science, 239, 487-491.

Vincent, B. \& Young, C.A. (1978). Equilibrium aspects of heteroflocculation in mixed stericallystabilised dispersions. Faraday Disc. Chem. Soc., 65, 296-305. 